\title{
Optimization of high-intensity pulsed electric field-assisted extraction of procyanidins from Vitis amurensis seeds using response surface methodology
}

\author{
Zhou Yong Dong ${ }^{1 *}$, Hua Hua Wang ${ }^{1}$, Ming Yue $\mathrm{Li}^{1}$, Wei Liu ${ }^{1}$, Tie Hua Zhang ${ }^{1}$ \\ ${ }^{1}$ College of Food Science and Engineering, Jilin University, 130062, Changchun, Jilin, China
}

\begin{abstract}
Procyanidins (PC) from Vitis amurensis seeds was extracted using high-intensity pulsed electric field (PEF). The process parameters including pulse number, electric field strength, ratio of material to liquid and ethanol concentration were studied using response surface methodology, and extraction yield of the extracts were determined. Antioxidant activity of the extracts by PEF, ultrasonic-assisted extraction (UAE), microwave-assisted extraction (MAE) and ethanol extraction (EAE) were compared based on total antioxidant capacity, DPPH radical scavenging capacity and ferrous ion chelating activity. The results revealed that the optimization of conditions of PEF are: pulse number 10; electric field strength $25 \mathrm{kV} / \mathrm{cm}$; ratio of material to liquid 1:21 g/mL; ethanol concentration $63 \%(\mathrm{v} / \mathrm{v})$, and the PC yields reached $8.23 \%$ under this condition. The PEF resulted in a highest extraction yield of PC among the four extraction methods. There was no significant difference in total antioxidant capacity of PC obtained by four methods, the DPPH radical scavenging capacity and ferrous ion chelating activity of PC extracted by PEF were close to that of UAE and MAE, which were superior to EAE. These showed that PEF was an effective method for extracting PC.
\end{abstract}

\section{Introduction}

Vitis amurensis is a perennial deciduous woody liana of Vitaceae family and originates from northeast and northern China, North Korea and Russian Far East. Although Vitis amurensis berries have a good value of edible use, it could be unfavorable for direct consumption because of its high acidity and heavy astringent taste. As a result, it is often used for wine making. And a large amount of by-products are generated at the same time, including outer peels and seeds while seeds accounted for nearly $75 \%$. According to the current research, vinification by-products containing high levels of various health enhancing substances is a potential inexpensive source of high added value antioxidants ${ }^{[1]}$ and an excellent raw material for extracting the PC. Nevertheless, most of them are not properly handled. So, the use of by-products has economic benefits to producers and positive impacts on the environment, bringing to a greater diversity of products.

PC constitutes a class of oligomeric and polymeric polyphenols with flavan-3-ols as monomeric building blocks. PC was reported to be the active ingredient, which exhibited various biological and pharmacological activities such as antioxidant activity, antimicrobial activity [2] and protection against dyslipidaemia [3]. Because of high security preservation and good bioavailability, it has been becoming a research hotspot being used for health care products.

Due to the shortcomings of traditional organic solvent extraction method, new extracting technologies of the PC such as ultrasonic-assisted extraction, microwave-assisted extraction and supercritical $\mathrm{CO}_{2}$ extraction are still the research hotspot. However, there are still some unsolved problems like time-consuming, high energy consumption and high impurity. PEF is an available technique for PC extraction. It has been shown to be promising as a milder and more efficient alternative to conventional cell disintegration techniques ${ }^{[4]}$. The material was treated by PEF with electric pulse. The narrow pulse would excite material to selffrequency oscillation, i.e. resonance vibration. Therefore, materials would produce huge energy by themselves and accelerate chemical reaction [5]. It would induce a permeability of cell membranes that facilitates the release of valuable compounds from the inner parts of the cells. Comparing it with other assistant extraction methods, due to its non-thermal impact on foodstuffs, PEF treatment may exert a selective permeability of the membranes (tonoplast and plasma membrane) whereas the cell wall remains intact, which improves the purity and the yield of the extracts ${ }^{[6]}$. Many studies have shown that it is an effective method which can improve the extractability ${ }^{[7-8]}$.

Antioxidants play a vital role in both food systems and human body to reduce oxidative processes. The

Corresponding author: dongzhouyong3421@163.com 
evaluation of the antioxidant activity of the PC has a practical significance for its further application. Due to the complexity of oxidative processes occurring in food or biological systems as well as the different antioxidative mechanisms by which various compounds may act, finding one method that can characterize the overall antioxidative potential of food is not an easy task [9]. Therefore, antioxidant activities of the PC were investigated based on the different antioxidant mechanisms in this study.

This work was mainly devoted to presenting a new method of extracting PC from Vitis amurensis seed. The extraction process was also optimized and compared the PC yield and antioxidant activity of which with other methods. The work provides a new way for the utilization of processing by-products of Vitis amurensis, and provides the theoretical basis and technical reference for the application of PC in health products.

\section{Materials and Methods}

\subsection{Materials}

Vitis amurensis seeds was supplied by Food Processing Technology Laboratory of Changchun Normal University (Jilin, China); Procyanidins (Shanghai Yuanye Bio Technology Co., Ltd., Shanghai, China; the purity of procyanidins was 95\%), vitamin C (Vc); ethylene diamine tetraacetate (EDTA); 2,2-diphenyl-1picrylhydrazyl(DPPH), anhydrous ethanol, petroleum ether, vanillin, methanol, hydrochloric acid, sodium hydroxide; salicylic acid, ferrous sulfate, hydrogen peroxide, phosphate, ferrozine and ferrous chloride were purchased from Sinopharm Chemical Reagent Co. Ltd. (Shanghai, China). All other reagents were of analytical grade.

\subsection{Sample Preparation}

The Vitis amurensis residue was collected after brewing. The seeds were separated and lyophilized by using a FD$1 \mathrm{C}-80$ freeze dryer. The dry seeds were ground in a mill to obtain a particle size that could pass through a 100 mesh sieve. The Oil in seeds was removed with Soxhlet extraction method. Then, the samples were kept in closed plastic bags to prevent oxidation at $-20^{\circ} \mathrm{C}$ until required.

\subsection{Determination of PC}

The content of PC was determined by vanillinhydrochloric acid method ${ }^{[10]}$ with some modifications. Standard solutions containing $0,0.1,0.2,0.3,0.4$ and 0.5 $\mathrm{mg} / \mathrm{mL}$ PC were prepared. Aliquots of $1.0 \mathrm{~mL}$ were transferred to five different test tubes, and then mixed with $6.0 \mathrm{~mL}$ of $4 \%(\mathrm{w} / \mathrm{v})$ vanillin methanol solution and $3.0 \mathrm{~mL} \mathrm{HCl}$. The mixture was kept at $30 \pm 1^{\circ} \mathrm{C}$ for $20 \mathrm{~min}$. The absorbance at $500 \mathrm{~nm}$ was checked and the standard PC absorbance curve was plotted. The sample was processed in the same way as for the standard PC solutions and the yield was determined using the equation:
The yield of procyanidins $(\%)=\frac{\mathrm{C} \times \mathrm{n} \times \mathrm{v}}{\mathrm{m}} \times 100$

where $C$ is the concentration of the PC $(\mathrm{mg} / \mathrm{mL}), n$ is the dilution multiple, $v$ is the volume of extract $(\mathrm{mL}), m$ is the quantity of sample $(\mathrm{g})$.

\subsection{PEF Process and Experimental Design}

\subsubsection{PEF Treatment System}

PEF extraction system (shown in Fig. 1) includes a high voltage pulse generator, an oscillograph, a coaxial liquid material treatment chamber, and a pump. The processing device has been described in the previous report ${ }^{[11]}$. It can generate exponentially decaying bipolar triangle pulse waveforms with a pulse duration of $2 \mu \mathrm{s}$. The bipolar pulse waveform and input voltage can be displayed on an oscillograph. The pulse number (n) is calculated as: $n=\pi r 2 l f / 1000 Q$, while the electric field strength $(E, k V / \mathrm{cm})$ is calculated as: $\mathrm{E}=V p-p / 2 l$. where $r$ is the radius of hole of treatment chamber, $l$ is the distance between two electrodes of treatment chamber, $f$ is the frequency $(\mathrm{Hz}), Q$ is the flow velocity, $V p-p$ is the input voltage which was showed by oscillograph $(\mathrm{kV}), V$ is the treatment quantity $(\mathrm{mL})$. In this paper, $r$ is $0.5 \mathrm{~mm}$, $l$ is $1.5 \mathrm{~mm}, V$ is $40 \mathrm{~mL}, Q$ is $10 \mathrm{~mL} / \mathrm{min}$, and other parameters are changed with the experimental condition.

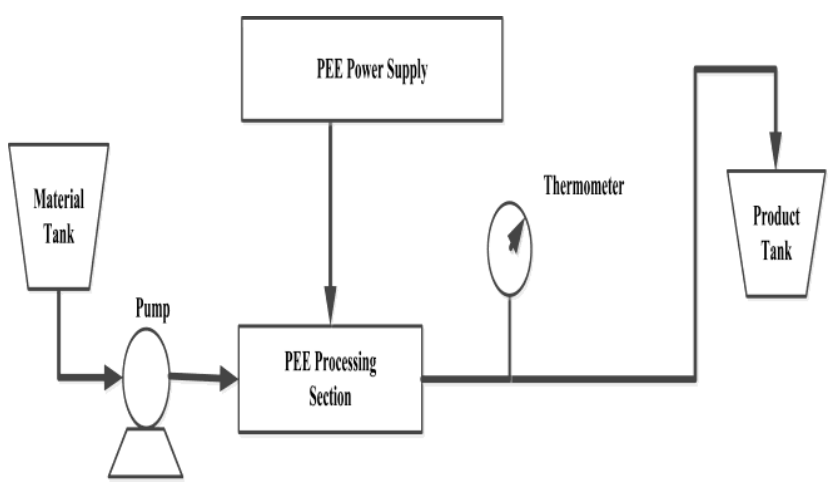

Fig. 1. Schematic Diagram of High Intensity Pulsed Electric Field (PEF) Processing Apparatus

\subsubsection{PEF Extraction Process}

Two grams of the degreased Vitis amurensis seeds powder was weighed and mixed with aqueous ethanol, then was extract with PEF treatment system. At the end of the extraction process, the mixtures were centrifuged at $4000 \mathrm{r}$ for $15 \mathrm{~min}$, and then the supernatant was collected and lyophilized for further analysis.

\subsubsection{Experimental Design for RSM}

On the basis of the preliminary experiment, a threelevel-four-factor BBD was applied to a set of 29 combinations of these variables to obtain the highest PC yield. The parameters were: pulse number $\left(X_{1}\right)$, electric field strength $\left(X_{2}\right)$, ratio of material to liquid $\left(X_{3}\right)$, and ethanol concentration $\left(X_{4}\right)$. PC yield $(Y)$ was selected as 
the response of the design experiments. The range of independent factors and their coded levels are given in Table 1 .

Table 1. Factors and levels for response surface design

\begin{tabular}{ccccc}
\hline \multirow{4}{c}{$\begin{array}{c}\text { Fode } \\
\mathrm{d} \\
\text { levels }\end{array}$} & $\begin{array}{c}X_{1} \text { (pulse } \\
\text { number) }\end{array}$ & $\begin{array}{c}X_{2} \text { (electric } \\
\text { field strength) } \\
\mathrm{kV} / \mathrm{cm}\end{array}$ & $\begin{array}{c}X_{3} \\
\text { (ratio of material to } \\
\text { liquid) } \\
\mathrm{g} / \mathrm{mL}\end{array}$ & $\begin{array}{c}X_{4} \text { (ethanol } \\
\text { concentration) } \\
\%\end{array}$ \\
\hline-1 & 8 & 20 & $1: 15$ & 50 \\
0 & 10 & 25 & $1: 20$ & 60 \\
1 & 12 & 30 & $1: 25$ & 70 \\
\hline
\end{tabular}

\subsection{Ethyl Alcohol Extraction (EAE) Process}

The extraction conditions were investigated with a method from that of Wang et al. ${ }^{[12]}$. The extraction process conditions of PC were extraction temperature of $60{ }^{\circ} \mathrm{C}$, ethanol concentration of $70 \%(\mathrm{v} / \mathrm{v})$, extraction time of $120 \mathrm{~min}$ and material/liquid ratio of $1: 5 \mathrm{~g} / \mathrm{mL}$.

\subsection{Ultrasonic-assisted Extraction Process}

(UAE)

An ultrasonic apparatus (KQ-400KDV, Kunshan, China) was employed for the extraction of PC from Vitis amurensis seeds. According to the method of Liu et al. [13] with some modifications, the conditions of ultrasonic-assisted extraction were ultrasonic power of $240 \mathrm{~W}$, ultrasound time of $20 \mathrm{~min}$, ethanol concentration of $60 \%(\mathrm{v} / \mathrm{v})$ and material/liquid ratio of $1: 20 \mathrm{~g} / \mathrm{mL}$.

\subsection{Microwave-assisted Extraction Process}

(MAE)

The MAE was carried out by microwave device (MM721AAU-PM, Midea, China). According to the method reported by Rong et al. ${ }^{[14]}$ and the experimental conditions with slightly modified, the conditions of microwave-assisted extraction of PC from Vitis amurentisis seeds were microwave power of $385 \mathrm{~W}$, microwave time of $70 \mathrm{~s}$, ethanol concentration of $60 \%$ $(\mathrm{v} / \mathrm{v})$ and material/liquid ratio of $1: 20 \mathrm{~g} / \mathrm{mL}$.

\subsection{Determination of Antioxidant Activities}

\subsubsection{Total Antioxidant Capacity Assay}

The total antioxidant capacity was performed by the method of Prieto et al. ${ }^{[15]}$, determined by using the phosphor-molybdenum complex method. $1.0 \mathrm{~mL} \mathrm{H}_{2} \mathrm{SO}_{4}$ (3 mol/L), $1.0 \mathrm{~mL} \mathrm{Na}_{3} \mathrm{PO}_{4}(0.14 \mathrm{~mol} / \mathrm{L}), 1.0 \mathrm{~mL}$ ammonium molybdate solution $(0.02 \mathrm{~mol} / \mathrm{L})$ were mixed in test tubes, and then different PC samples liquid and $\mathrm{Vc}$ (concentrations were $0.01,0.02,0.04,0.06,0.08,0.1$ $\mathrm{mg} / \mathrm{mL}$ ) were added, respectively. Distilled water was added to a constant volume of $5.0 \mathrm{~mL}$, shaking with gasser and the mixture was heated at $95^{\circ} \mathrm{C}$ for $90 \mathrm{~min}$. Then remove and cool to room temperature. The absorbance was measured at a wavelength of $695 \mathrm{~nm}$. Distilled water was used as a blank control.

\subsubsection{DPPH Radical Scavenging Assay}

The DPPH radical scavenging activity assay was conducted according to the method of Shimada et al. ${ }^{[16]}$ with some modifications. $2.5 \mathrm{~mL}$ of sample solution was mixed with $2.5 \mathrm{~mL}$ of DPPH solution $(0.1 \mathrm{mmol} / \mathrm{L}$ in $95 \%$ ethanol). The mixture was reacted for $20 \mathrm{~min}$ at room temperature in the dark and the absorbance was measured at $517 \mathrm{~nm}$. For the blank, $2.5 \mathrm{~mL}$ of distilled water was used instead of the sample. Vc was served as a positive control. The DPPH radical scavenging activity was calculated using the following equation:

Scavenging activity $(\%)=\left(1-\frac{\mathrm{A}_{1}-\mathrm{A}_{2}}{\mathrm{~A}_{3}}\right) \times 100$

where $A_{3}$ is the absorbance of the control (without extract), $A_{1}$ is the absorbance of the sample addition and $A_{2}$ is the absorbance without DPPH.

\subsubsection{Ferrous Ion Chelating Assay}

Ferrous ion chelating activity was evaluated by the method of Dinis et al. ${ }^{[17]}$ with some modifications. 1.0 $\mathrm{mL}$ of sample was dissolved in $2.0 \mathrm{~mL}$ distilled water. Subsequently, $0.05 \mathrm{~mL}$ of $2 \mathrm{mM}$ ferrous chloride solution was added and reaction for 3 minutes, then the reaction was inhibited by the addition of $5 \mathrm{mM}$ ferrozine $(0.1 \mathrm{~mL})$. The mixture was shaken vigorously and left at room temperature for $10 \mathrm{~min}$. Absorbance of the resulting solution was measured at $562 \mathrm{~nm}$. A control was made with $1 \mathrm{~mL}$ of distilled water instead of sample and EDTA was used as a reference. The chelating capacity was calculated using the following equation:

Ferrousion chelating activity $(\%)=\left(1-\frac{\mathrm{A}_{1}}{\mathrm{~A}_{0}}\right) \times 100$

where $A_{1}$ is the absorbance of the sample addition and $A_{0}$ is the absorbance without sample.

\subsection{Statistical Analysis}

The results were processed using Origin 8.1. The data were subjected to analysis of variance (ANOVA). All experiments were performed in triplicate and data are expressed as mean \pm standard deviation (SD). $P$ values $<$ 0.05 were regarded as significant. The DesignExpert.V8.0.6 software was employed for the regression analysis and the graphical optimization.

\section{Results and Discussion}

\subsection{Optimization of Extraction Conditions}

The values of the process variables and the observed values of the response are given in Table 2 . The yield ranged from 6.52 to $8.21 \%$ for the corresponding extraction conditions. Through multiple linear regression (MLR), the observed yield of PC could be expressed using the following second-order polynomial equation in terms of coded values: where $Y$ is the PC yield (\%) and $X_{1}, X_{2}, X_{3}$ and $X_{4}$ are the coded values of the pulse number, electric field strength, ratio of material to liquid, and ethanol concentration, respectively. 
Table 2. Box-Behnken experimental design and results for response surface analysis

\begin{tabular}{|c|c|c|c|c|c|}
\hline \multirow{2}{*}{$\begin{array}{l}\text { Experi } \\
\text { ments }\end{array}$} & \multicolumn{4}{|c|}{ Coded levels } & \multirow{2}{*}{$\begin{array}{c}\mathrm{PC} \\
\text { yield } \\
(\%)\end{array}$} \\
\hline & $X_{1}$ & $X_{2}$ & $X_{3}$ & $X_{4}$ & \\
\hline 1 & -1 & -1 & 0 & 0 & 7.92 \\
\hline 2 & -1 & 0 & 0 & 1 & 7.69 \\
\hline 3 & 0 & 0 & -1 & 1 & 7.27 \\
\hline 4 & 0 & -1 & 0 & 1 & 7.89 \\
\hline 5 & 0 & 0 & 0 & 0 & 8.2 \\
\hline 6 & 0 & 0 & 1 & -1 & 6.74 \\
\hline 7 & 0 & 1 & -1 & 0 & 7.4 \\
\hline 8 & 0 & 0 & 0 & 0 & 8.18 \\
\hline 9 & 0 & -1 & -1 & 0 & 7.52 \\
\hline 10 & 0 & 1 & 0 & -1 & 7.21 \\
\hline 11 & 1 & 0 & 0 & -1 & 6.68 \\
\hline 12 & 0 & -1 & 0 & -1 & 6.52 \\
\hline 13 & 0 & 0 & 0 & 0 & 8.16 \\
\hline 14 & 0 & 0 & -1 & -1 & 6.66 \\
\hline 15 & 0 & 1 & 0 & 1 & 7.27 \\
\hline 16 & 0 & 0 & 1 & 1 & 7.71 \\
\hline 17 & 1 & 0 & -1 & 0 & 7.55 \\
\hline 18 & 0 & 0 & 0 & 0 & 8.08 \\
\hline 19 & 0 & -1 & 1 & 0 & 7.59 \\
\hline 20 & -1 & 0 & 0 & -1 & 7.46 \\
\hline 21 & 0 & 0 & 0 & 0 & 8.21 \\
\hline 22 & 1 & -1 & 0 & 0 & 7.59 \\
\hline 23 & -1 & 1 & 0 & 0 & 7.69 \\
\hline 24 & 1 & 1 & 0 & 0 & 8.04 \\
\hline 25 & 0 & 1 & 1 & 0 & 7.7 \\
\hline 26 & -1 & 0 & -1 & 0 & 7.56 \\
\hline 27 & 1 & 0 & 0 & 1 & 8.02 \\
\hline 28 & -1 & 0 & 1 & 0 & 8 \\
\hline 29 & 1 & 0 & 1 & 0 & 7.61 \\
\hline
\end{tabular}

$Y=8.17-0.069 X_{1}+0.023 X_{2}+0.12 X_{3}+0.38 X_{4}+0.17 X_{1} X_{2}-$ $0.095 X_{1} X_{3}+0.28 X_{1} X_{4}+0.057 X_{2} X_{3}-0.33 X_{2} X_{4}+0.090 X_{3} X_{4}$ $0.077 X_{1}^{2}-0.26 X_{2}^{2}-0.39 X_{3}^{2}-0.66 X_{4}^{2}$

Analysis of variance for the developed regression model is presented in Table 3 . The $P$-value for the model was less than 0.0001 which indicated the fitness of model was significant. Moreover, the $P$-value of the lack of fit in this model was 0.2106 , which implied that the degree of lack of fit was not significant. And in this paper, the $R^{2}$ value of the model was 0.9885 . So, both the lack of fit values and the $R^{2}$ value showed that the regression model had well defined the true behavior of the system.

The effects of pulse number, electric field strength, ratio of material to liquid, ethanol concentration and their interactions on the PC yield were shown in Fig. 2. According to statistical analysis (Table 3) and response surface plots (Fig. 2), the one-degree term of ratio of material to liquid $\left(X_{3}\right)$, ethanol concentration $\left(X_{4}\right)$, pulse number $\left(X_{1}\right)$, the interaction term of pulse number and ethanol concentration $\left(X_{1} X_{4}\right)$, electric field strength and ethanol concentration $\left(X_{2} X_{4}\right)$, pulse number and electric field strength $\left(X_{1} X_{2}\right)$, and the quadratic term of electric field strength $\left(X_{2}^{2}\right)$, ratio of material to liquid $\left(X_{3}^{2}\right)$, and ethanol concentration $\left(X_{4}^{2}\right)$ were extremely significant $(P<0.01)$. The interaction term of pulse number and ratio of material to liquid $\left(X_{1} X_{3}\right)$, ratio of material to liquid and ethanol concentration $\left(X_{3} X_{4}\right)$, and the quadratic term of pulse number $\left(X_{1}^{2}\right)$ were significant $(P<0.05)$ and other not significant $(P>0.05)$.
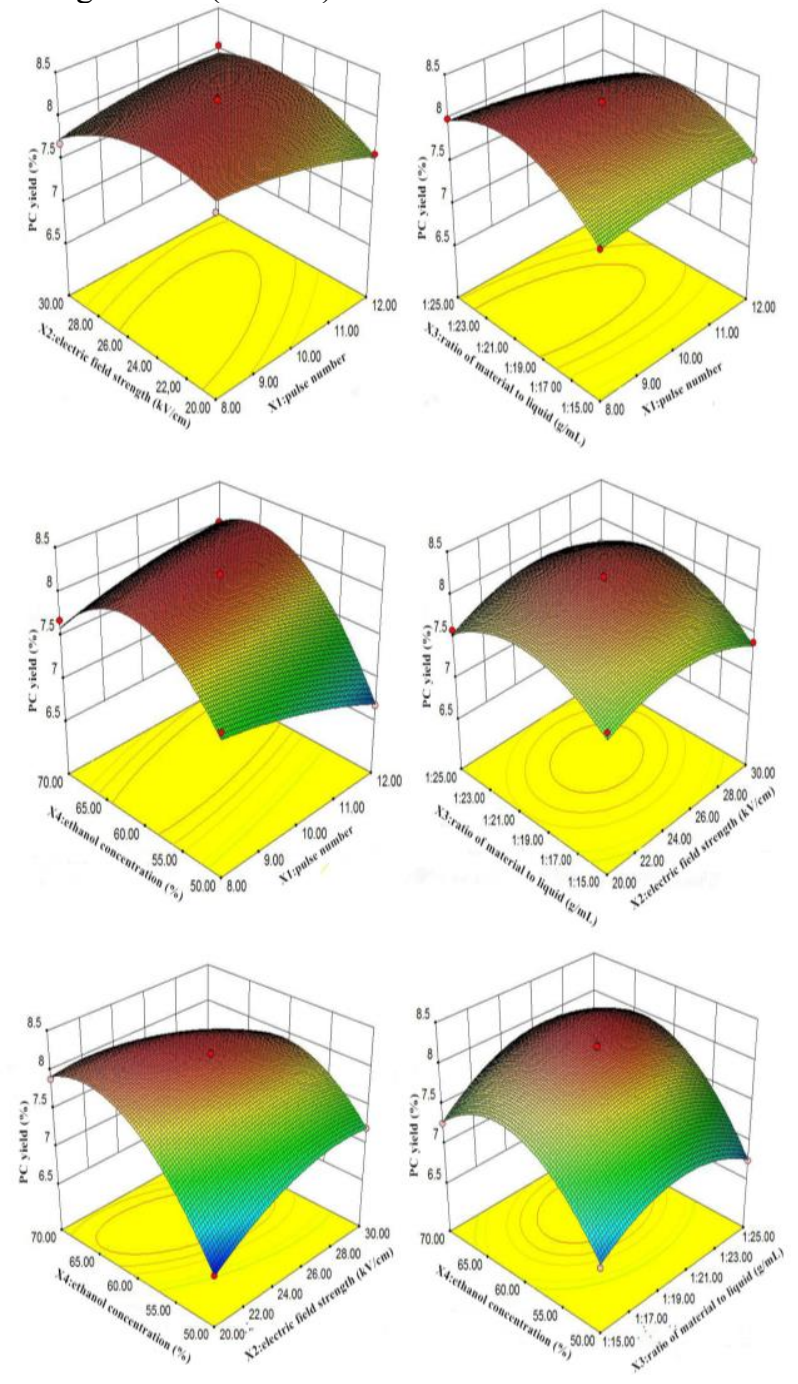

Fig. 2. Response surface graphs showing the experimental factors and their combined effects on PC extraction

Through prediction by this model, the optimal conditions to obtain the highest yield of PC were determined as follows: pulse number $\left(X_{1}\right) 10$, electric field strength $\left(X_{2}\right) 24.30 \mathrm{kV} / \mathrm{cm}$, ratio of material to liquid $\left(X_{3}\right)$ 1:20.88 $\mathrm{g} / \mathrm{mL}$, and ethanol concentration $\left(X_{4}\right)$ $63.31 \%$. Under this condition, the predicted yield of PC was $8.24 \%$. For practical purposes, we set the optimal conditions to pulse number $\left(X_{1}\right)$ 10, electric field strength $\left(X_{2}\right) 25 \mathrm{kV} / \mathrm{cm}$, ratio of material to liquid $\left(X_{3}\right)$ $1: 21 \mathrm{~g} / \mathrm{mL}$, and ethanol concentration $\left(X_{4}\right) 63 \%(\mathrm{v} / \mathrm{v})$, the yield of PC was $8.23 \pm 0.03 \%$, which was very similar to the predicted value. 
Table 3. Analysis of variance for the developed regression model

\begin{tabular}{|c|c|c|c|c|c|c|}
\hline Source & $\begin{array}{l}\text { Degrees } \\
\text { of } \\
\text { freedom }\end{array}$ & $\begin{array}{c}\text { Sum } \\
\text { of squares }\end{array}$ & $\begin{array}{l}\text { Mean } \\
\text { square }\end{array}$ & F-value & $\begin{array}{l}\text { p-value } \\
\text { Prob }>F\end{array}$ & $\mathrm{~s}$ \\
\hline Model & 14 & 6.37 & 0.45 & 85.81 & $<0.0001$ & ** \\
\hline$X_{1}$ & 1 & 0.057 & 0.057 & 10.83 & 0.0054 & ** \\
\hline$X_{2}$ & 1 & $\begin{array}{c}6.533 \mathrm{E}- \\
003\end{array}$ & $\begin{array}{c}6.533 \mathrm{E}- \\
003\end{array}$ & 1.23 & 0.2856 & \\
\hline$X_{3}$ & 1 & 0.16 & 0.16 & 30.38 & $<0.0001$ & ** \\
\hline$X_{4}$ & 1 & 1.75 & 1.75 & 329.84 & $<0.0001$ & ** \\
\hline$X_{1} X_{2}$ & 1 & 0.12 & 0.12 & 21.81 & 0.0004 & ** \\
\hline$X_{1} X_{3}$ & 1 & 0.036 & 0.036 & 6.81 & 0.0206 & * \\
\hline$X_{1} X_{4}$ & 1 & 0.31 & 0.31 & 58.12 & $<0.0001$ & ** \\
\hline$X_{2} X_{3}$ & 1 & 0.013 & 0.013 & 2.50 & 0.1365 & \\
\hline$X 2 X_{4}$ & 1 & 0.43 & 0.43 & 80.95 & $<0.0001$ & ** \\
\hline$X_{3} X_{4}$ & 1 & 0.032 & 0.032 & 6.11 & 0.0269 & * \\
\hline$X_{1}^{2}$ & 1 & 0.039 & 0.039 & 7.29 & 0.0173 & $*$ \\
\hline$X_{2}^{2}$ & 1 & 0.44 & 0.44 & 83.32 & $<0.0001$ & $* *$ \\
\hline$X_{3}{ }^{2}$ & 1 & 0.98 & 0.98 & 185.84 & $<0.0001$ & $* *$ \\
\hline$X_{4}^{2}$ & 1 & 2.85 & 2.85 & 538.69 & $<0.0001$ & $* *$ \\
\hline Residual & 14 & 0.074 & $\begin{array}{c}5.300 \mathrm{E}- \\
003\end{array}$ & & & \\
\hline Lack of Fit & 10 & 0.063 & $\begin{array}{c}6.347 \mathrm{E}- \\
003\end{array}$ & 2.37 & 0.2106 & \\
\hline Pure Error & 4 & 0.011 & $\begin{array}{c}2.680 \mathrm{E}- \\
003\end{array}$ & & & \\
\hline Sum & 28 & 6.44 & & & & \\
\hline \multicolumn{7}{|c|}{$R$-Squared $=0.9885$} \\
\hline
\end{tabular}

Note: $* P<0.05 ; * * P<0.01$.

\subsection{Comparison of the Yields of PC Among Different Methods}

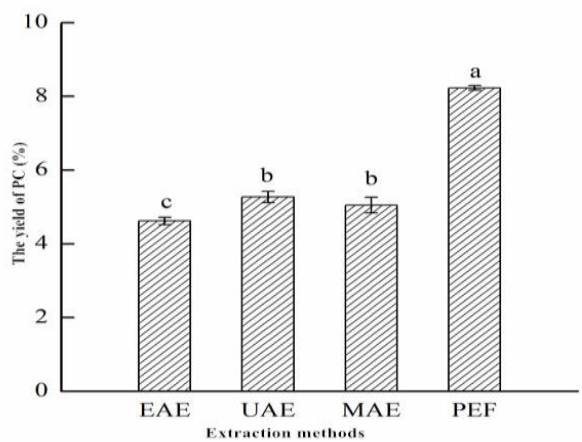

Fig.3. Effect of different extraction methods on the yield of procyanidins. Note: different letters indicate significant differences between different samples $(P<0.05)$.

The yield of PC from Vitis amurensis seeds by ethyl alcohol extraction, ultrasonic-assisted extraction, microwave-assisted extraction and PEF extraction were shown in Fig. 3. It indicated that PEF, UAE, and MAE methods could improve the PC yield and short the extraction time compared with EAE method. The yield of PC extracted by PEF was $1.78,1.56$ and 1.63 times higher than that of EAE, UAE and MAE, respectively. Boussetta et al. ${ }^{[18]}$ researched the influence of pulsed electrical discharges of low energy ( 3 to $10 \mathrm{~J}$ ) on the extraction of polyphenols from grape seeds. The optical experiment showed that the mechanical effects of arcs (shock waves, expanding cavity, and strong turbulence) were much more pronounced compared to streamers. These mechanical effects were responsible for the fragmentation of grape seeds, and strongly promoted the release of polyphenols. The electrical treatments can also damage cell membranes and cell walls thus accelerating the compounds extraction ${ }^{[19]}$. Puértolas et al. ${ }^{[7]}$ research showed that PEF treatment could improve the yield of anthocyanin extraction from purple-fleshed potato. It indicated that PEF extraction was a more efficient extraction method because of mechanical effects. PEF extraction is carried out at room temperature, belonging to the non-heat treatment, not only save energy, but also avoid the damaging effects of heat treatment and conducive to maintaining the activity of PC.

\subsection{Comparison of Antioxidant Activity}

The phosphomolybdenum method is based on the reduction of Mo (VI) to Mo $(\mathrm{V})$ by the antioxidant compounds from the extract and subsequent formation of a green phosphate/Mo (V) complex with a maximal absorption at $695 \mathrm{~nm}{ }^{[15]}$. Total antioxidant capacity of PC by different extraction methods and Vc are shown in Fig. 4. A linear increase in total antioxidant capacity of sample was observed over the concentration range 0.10$0.35 \mathrm{mg} / \mathrm{mL}$. There is no significant correlation $(P>$ 0.05 ) about the total antioxidant capacities of PC among different extraction methods. The absorption values of PC $C_{\mathrm{PEF}}, \mathrm{PC}_{\mathrm{UAE}}, \mathrm{PC}_{\mathrm{MAE}}$ and $\mathrm{PC}_{\mathrm{EAE}}$ were $0.659 \pm 0.021$, $0.591 \pm 0.018,0.598 \pm 0.009,0.619 \pm 0.012$ respectively at the concentration of $0.35 \mathrm{mg} / \mathrm{mL}$. The total antioxidant action of reductones was based on the breaking of the free radical chain by donating a hydrogen atom, thus preventing peroxide formation ${ }^{[20]}$. The total antioxidant capacity of the extracts were all good by the four methods and indicated that the marked total antioxidant activity of extracts seems to be due to presence of PC which may act by donating the electrons and reacting with free radicals to convert them to more stable product and terminate free radical chain reaction. Chen et al. [21] used four methods (solvent extraction, ultrasonicassisted extraction, microwave-extraction and ultrasonic treatment followed by microwave extraction) to extract PC from Xinjiang Turpan Cabernet Sauvignon grape seed and studied its total antioxidant capacity. The results showed that there was no significant difference in total antioxidant capacity among four extraction treatments. This is consistent with the results of the study.

DPPH is a stable free radical that has been used to evaluate the free-radical scavenging activity. When DPPH radicals encounter a proton-donating substrate such as an antioxidant, the radicals would be scavenged and the absorbance is reduced [16]. The DPPH radical scavenging activity of $\mathrm{PC}_{\mathrm{PEF}}, \mathrm{PC}_{\mathrm{UAE}}, \mathrm{PC}_{\mathrm{MAE}}, \mathrm{PC}_{\mathrm{EAE}}$ and $\mathrm{Vc}$ are shown in Fig. 4. B. The $\mathrm{IC}_{50}$ values of $\mathrm{PC}_{\mathrm{PEF}}$, $\mathrm{PC}_{\mathrm{MAE}}, \mathrm{PC}_{\mathrm{UAE}}, \mathrm{PC}_{\mathrm{EAE}}$ and $\mathrm{Vc}$ were $0.169 \pm 0.006$, $0.170 \pm 0.009, \quad 0.184 \pm 0.012, \quad 0.565 \pm 0.021, \quad$ and $0.115 \pm 0.017 \mathrm{mg} / \mathrm{mL}$, respectively. We can conclude that the DPPH radical scavenging activity of $\mathrm{PC}_{\mathrm{PEF}}$ is slightly higher than that of $\mathrm{PC}_{\mathrm{UAE}}$ and $\mathrm{PC}_{\mathrm{MAE}}$, significantly higher than that of $\mathrm{PC}_{\mathrm{EAE}}$ from the $\mathrm{IC}_{50}$ values and curves of Fig. 4. B. The biological abilities of PC largely depend on their structure, particularly the molecular weight that is also expressed as the degree of polymerization (DP) ${ }^{[22]}$. The high extraction temperature and the extended extraction time lead to degradation of the PC polymer during the EAE process, resulting in its DPPH radical scavenging capacity reduced. The results of Spranger ${ }^{[23]}$ showed that the scavenging activity of 
grape seed procyanidins on DPPH is positively related to their degree of polymerization, i.e., polymer > oligomer $>$ monomer (catechin). Zhou et al. ${ }^{[24]}$ showed that the higher polymerization degree of polymeric proanthocyanidins from litchi fruit stones exhibited higher DPPH radical scavenging activity than those from litchi pericarps.

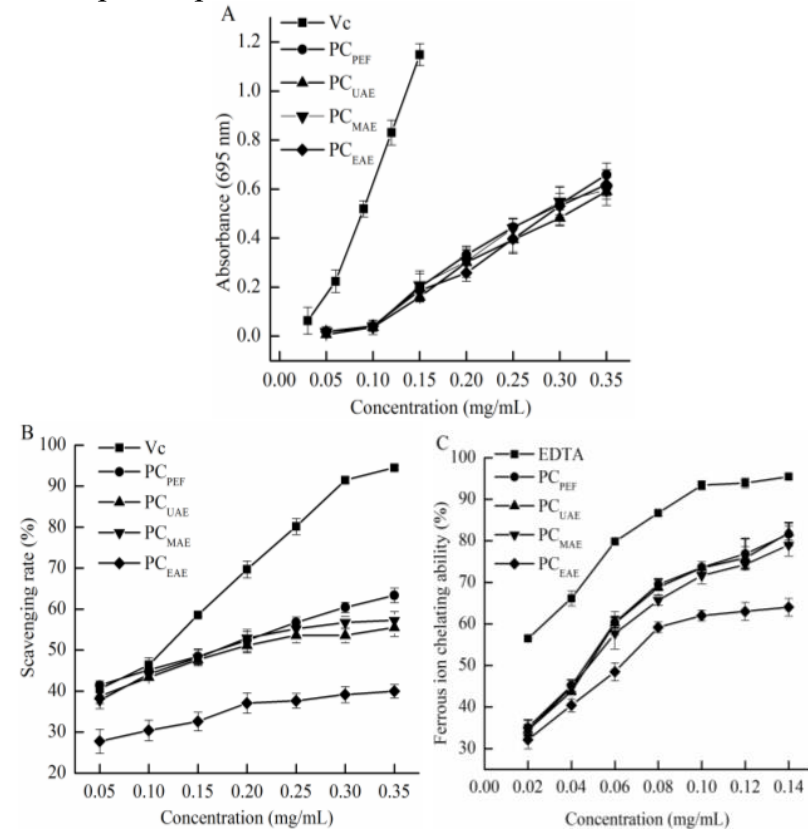

Fig. 4. The antioxidant capacity of $\mathrm{PC}$ (A: Total antioxidant capacity; B: DPPH radical scavenging activity; C: Ferrous ion chelating capacity)

Presence of transition metal ions could catalyse the Haber-Weiss and Fenton-type reactions, resulting in generation of hydroxyl radicals $(\mathrm{OH} \bullet)$ and reduce the redox potential, thereby stabilizing the oxidized form of the metal ion. ${ }^{[20]}$. Analysis of ferrous ion chelating activity of these extracts of PC shows a dose dependent ferrous ion chelating activity. As shown in Fig. 4. C, the ferrous ion chelating capacity of EDTA was $56.487 \%$ at $0.02 \mathrm{mg} / \mathrm{mL}$ (the lowest concentration of this experiment). Contrast analysis found that the $\mathrm{IC}_{50}$ of $\mathrm{PC}_{\mathrm{PEF}}, \mathrm{PC}_{\mathrm{UAE}}, \mathrm{PC}_{\mathrm{MAE}}$ and $\mathrm{PC}_{\mathrm{EAE}}$ were $0.046 \pm 0.003$, $0.047 \pm 0.005, \quad 0.048 \pm 0.002, \quad 0.063 \pm 0.006 \mathrm{mg} / \mathrm{mL}$, respectively. The ferrous ion chelating ability of the $\mathrm{PC}_{\mathrm{PEF}}$ is close to that of $\mathrm{PC}_{\mathrm{UAE}}$ and $\mathrm{PC}_{\mathrm{MAE}}$, higher than that of $\mathrm{PC}_{\mathrm{EAE}}$. Shahidi et al. ${ }^{[25]}$ found that certain phenolic come possessing ortho dihydroxyl groups or a properly located carbonyl and hydroxyl groups, the more the hydroxyl and carbonyl groups in appropriate positions, the higher the chelating ability of the molecule could exhibit. Polyphenolic compounds, such as proanthocyanidins have been considered as strong iron chelating agents ${ }^{[26]}$. Maqsood and Benjakul ${ }^{[27]}$ have found that catechins have the higher metal chelating activity due to polyhydroxy structures. Furthermore Perva-Uzunalic et al. ${ }^{[28]}$ studied that degradation of catechins was observed at higher extraction temperatures and with prolonged extraction times. PEF and UAE are carried out at room temperature, belonging to the nonheat treatment, however, MAE (even though extraction time is short) and EAE belong to high temperature extraction methods. These may lead to the degradation of PC components during the extraction process.

\section{Conclusions}

An efficient PEF method for the extraction of PC from Vitis amurensis seeds was presented in this study. Response surface methodology (RSM) based on BoxBehnken design (BBD) was used for the optimization of conditions as follows: pulse number, 10; electric field strength, $25 \mathrm{kV} / \mathrm{cm}$; ratio of material to liquid, 1:21 $\mathrm{g} / \mathrm{mL}$; ethanol concentration, $63 \%(\mathrm{v} / \mathrm{v})$. PC yields reached $8.23 \pm 0.03 \%$ under this condition.

The comparative experiment of different extraction methods showed that the yield of PC extracted by PEF were $1.78,1.56$ and 1.63 times higher than that of EAE, UAE and MAE, respectively. The experiment of antioxidant activity showed that there was no significant difference in total antioxidant capacity of PC extracted by PEF, UAE, MAE and EAE, but the DPPH radical scavenging capacity and ferrous ion chelating activity of PC extracted by PEF were close to that of UAE and MAE, which were superior to EAE.

It could be concluded that the PEF was a non-thermal and efficient method, which had the higher speed, no negative effect and consumed lower energy. This offers an available way to efficient use of Vitis amurensis processing by-products. The research also provides reference for the application of PEF in the extraction of other active components.

\section{Acknowledgments}

This study was funded by the science and technology planning project of Jilin Province (SF2017-6-4). The authors acknowledge the Food Processing Technology Laboratory of Changchun Normal University (Jilin, China) for providing the Vitis amurensis seeds for the research.

\section{References}

1. Anastasiadi, M., Pratsinis, H., Kletsas, D., et al. (2010) Bioactive non-coloured polyphenols content of grapes, wines and vinification by-products: evaluation of the antioxidant activities of their extracts. J. Food Res. Int., 43: 805-813.

2. Martins G. R., Amaral F. R. L., Brum F. L., et al. (2020) Chemical characterization, antioxidant and antimicrobial activities of açaí seed (Euterpe oleracea Mart.) extracts containing A- and B-type procyanidins. LWT-Food Science and Technology., 132:1-11.

3. Quesada, H., Bas, J.M.D., Pajuelo, D., et al. (2009) Grape seed proanthocyanidins correct dyslipemia associated with a high-fat diet in rats and repress genes controlling lipogenesis and VLDL assembling in liver. J. Obesity, 33: 1007-1012. 
4. Donsì, F., Ferrari, G., Pataro, G. (2010) Applications of pulsed electric field treatments for the enhancement of mass transfer from vegetable tissue. J. Food Eng. Rev., 2: 109-130.

5. Yin, Y.G., He, G.D. (2008) A fast high-intensity pulsed electric fields (PEF)-assisted extraction of dissoluble calcium from bone. J. Sep. Purif. Technol., 61: 148-152.

6. Jaeger, H., Schulz, M., Lu, P., et al. (2012) Adjustment of milling, mash electroporation and pressing for the development of a pef assisted juice production in industrial scale. J. Innov. Food Sci. Emerg. Technol., 14: 46-60.

7. Puértolas, E., Cregenzán, O., Luengo, E., et al. (2013) Pulsed-electric-field-assisted extraction of anthocyanins from purple-fleshed potato. J. Food Chem, 136: 1330-1336.

8. Roohinejad, S., Everett, D.W., Oey, I. (2014) Effect of pulsed electric field processing on carotenoid extractability of carrot puree. J. Food Sci. Technol, 49: 2120-2127.

9. Samaranayaka, A.G.P., Li-Chan, E.C. Y. (2011) Food-derived peptidic antioxidants: a review of their production, assessment, and potential applications. J. Funct. Food., 3: 229-254.

10. Sun, B., Ricardodasilva, J.M., Spranger, I. (1998) Critical factors of vanillin assay for catechins and proanthocyanidins. J. Agric. Food Chem., 46: 4267-4274.

11. He, G.D., Yin, Y.G., Yan, X.X., et al. (2017) SemiBionic Extraction of Effective Ingredient from Fishbone by High Intensity Pulsed Electric Fields. J. Journal of Food Process Engineering, 40.

12. Wang, X.W., Zhao, Y., Shen, Y.J. (2011) Optimization of procyanidins extraction from Vitis amurensis seeds. J. Food Sci, 32: 21-24.

13. Liu, X.N., Kang, J., Zhao, J.L. (2016) Study on extraction process of Proanthocyanidins from black glutinous corn by response surface ultrasound. J. Food Ind, 128-131.

14. Rong, X., Zhang, X.L., Li, T.Z. (2016) Optimization of microwave assisted extraction of Proanthocyanidins from prickly seeds by response surface test. J. Food Sci, 37: 41-46.

15. Prieto, P., Pineda, M., Aguilar, M. (1999) Spectrophotometric quantitation of antioxidant capacity through the formation of a phosphomolybdenum complex: specific application to the determination of vitamin E. J. Anal. Biochem., 269: 337-341.

16. Shimada, K., Fujikawa, K., Yahara, K., et al. (1992) Antioxidative properties of xanthan on the autoxidation of soybean oil in cyclodextrin. J. Agric. Food Chem., 40: 945-948.

17. Dinis, T.C.P., Madeira, V.M.C., Almeidam, L.M. (1994) Action of phenolic derivates (acetoaminophen, salycilate, and 5-aminosalycilate) as inhibitors of membrane lipid peroxidation and peroxyl radicals scavengers. J. Archives of Biochemistry and Biophysics, 315: 161-169.

18. Boussetta, N., Lesaint, O., Vorobiev, E. (2013) A study of mechanisms involved during the extraction of polyphenols from grape seeds by pulsed electrical discharges. J. Innovative Food Science \& Emerging Technologies, 19: 124-132.

19. Boussetta, N., Vorobiev, E., Le, L.H., et al. (2012) Application of electrical treatments in alcoholic solvent for polyphenols extraction from grape seeds. Food Science and Technology, 46: 127-134.

20. Gordon, M.F., (1990) The Mechanism of antioxidant action in vitro. In: Hudson, B.J.F. (Eds.), Food antioxidants. Elsevier Applied Science, London. 1-18.

21. Chen, Y.R., Kang, J., Zhao, F.R. (2014) Antibacterial and antioxidant activity of procyanidins from grape seeds of Cabernet Sauvignon. J. Food Sci. Technol., 39: 209-215.

22. Craft, B.D., Kerrihard, A.L., Amarowicz, R., et al. (2012) Phenol-based antioxidants and the in vitro methods used for their assessment. J. Comprehensive Reviews in Food Science and Food Safety, 11: 148-173.

23. Spranger, I., Sun, B., Mateus, A.M., et al. (2008) Chemical characterization and antioxidant activities of oligomeric and polymeric procyanidin fractions from grape seeds. J. Food Chem, 108: 519-532.

24. Zhou, H.C., Lin, Y.M., Li, Y.Y., et al. (2011) Antioxidant properties of polymeric proanthocyanidins from fruit stones and pericarps of Litchi chinensis Sonn. J. Food Research International, 44: 613-620

25. Shahidi, F., Liyana-Pathirana, C.M., Wall, D.S. (2006) Antioxidant activity of white and black sesame seeds and their hull fractions. J. Food Chem, 99: 478-483.

26. Mira, L., Fernandez, M,T., Santos, M., et al. (2002) Interaction of flavonoids with iron and copper ions: a mechanism for their antioxidant activity. J. Free Radical Research, 36: 1199-1208.

27. Maqsood, S., Benjakul, S. (2010) Comparative studies of four different phenolic compounds on in vitro antioxidative activity and the preventive effect on lipid oxidation of fish oil emulsion and fish mince. J. Food Chemistry, 119: 123-132.

28. Perva-Uzunalic, A., Skerget, M., Knez, Z., et al. (2006) Extraction of active ingredients from green tea (Camellia sinensis): Extraction efficiency of major catechins and caffeine. J. Food Chemistry, 96: 597-605. 